\title{
Effects of Alloy Composition and Solid-State Diffusion Kinetics on Powder Bed Fusion Cracking Susceptibility
}

\author{
Holden Hyer ${ }^{1} \cdot$ Le Zhou $^{1} \cdot$ Abhishek Mehta ${ }^{1}$ Yongho Sohn ${ }^{1}$
}

Submitted: 7 July 2020/in revised form: 17 September 2020/Accepted: 12 October 2020/Published online: 5 November 2020 (C) ASM International 2020

\begin{abstract}
Laser powder bed fusion (LPBF) has demonstrated its unique ability to produce customized, complex engineering components. However, processing of many commercial Al-alloys by LPBF remains challenging due to the formation of solidification cracking, although they are labelled castable or weldable. In order to elucidate this divergence, solidification cracking susceptibility from the steepness of the solidification curves, specifically $\operatorname{ld} T / \mathrm{d} f_{\mathrm{S}}^{1 / 2}$, as the fraction solidified nears 1 towards complete solidification, was calculated via Scheil-Gulliver model as a function of solute concentration in simple binary Al-Si, Al$\mathrm{Mg}$, and $\mathrm{Al}-\mathrm{Cu}$ systems. Introduction of "diffusion in solid" into Scheil-Gulliver model resulted in a drastic reduction in the cracking susceptibility (i.e., reduction in the magnitude of $\left.\left|\mathrm{d} T / \mathrm{d} f_{\mathrm{S}}^{1 / 2}\right|\right)$ and a shift in the maximum $\left|\mathrm{d} T / \mathrm{d} f_{\mathrm{S}}^{1 / 2}\right|$ to higher concentrations of solute. Overall, the calculated solidification cracking susceptibility correlated well with experimental observation made using LPBF AA5083 (e.g., Al$\mathrm{Mg}$ ) and Al-Si binary alloys with varying Si concentration. Cracking susceptibility was found to be highly sensitive to the composition of the alloy, which governs the variation of $\left|\mathrm{d} T / \mathrm{d} f_{\mathrm{S}}^{1 / 2}\right|$. Furthermore, experimental observation suggests that the contribution of "diffusion in solids" to reduce the cracking susceptibility can be more significant than what is expected from an instinctive assumption of
\end{abstract}

Yongho Sohn

Yongho.Sohn@ucf.edu

Holden Hyer

hhyer@knights.ucf.edu

1 Department of Materials Science and Engineering, Advanced Materials Processing and Analysis Center, University of Central Florida, Orlando, FL 32816 negligible diffusion and rapid cooling typically associated with LPBF.

Keywords additive manufacturing $\cdot$ aluminum alloy cracking susceptibility $\cdot$ diffusion $\cdot$ laser powder bed fusion

\section{Introduction}

Additive manufacturing (AM) has demonstrated repeated success in producing customized components, previously restricted by the limitations of subtractive manufacturing via traditional materials processing methods. ${ }^{[1-3]}$ Laser powder bed fusion (LPBF) is a popular AM technique that has shown to produce dense, complex parts, built by repeated melting of a powder bed with a laser source in a layer by layer process. ${ }^{[1-3]}$ Unfortunately, LPBF of certain Al-alloys such as high strength AA7075 and corrosion resistant AA5083 is limited by the extensive formation of solidification cracking and/or excessive porosity. ${ }^{[4-7]}$ Predominantly, $\mathrm{Al}$ alloyed with near eutectic compositions of $\mathrm{Si}, \sim 12.6$ wt. $\%,{ }^{[8]}$ such as Al-10 wt.\% Si-0.5 wt.\% Mg (known as AlSi10Mg), have had success with building crack-free parts with LPBF. ${ }^{[9-11]}$ AlSi10Mg was adopted from casting as the high concentration of Si decreases the viscosity of the melt, allowing for a higher degree of flowability, desired in casting. ${ }^{[12]}$ Moreover, the near eutectic composition reduces the freezing range, easing transformation from liquid to solid without excessive strain accumulation that causes solidification cracking. ${ }^{[11-13]}$

Early investigation by Singer and Jennings ${ }^{[14]}$ suggested that solidification cracking is a result of increasing freezing range (i.e., commonly referred to as hot shortness range), which varies as a function of solute 
concentration. ${ }^{[15]}$ Solidification cracking models, such as that proposed by Clyne and Davies (CSD) ${ }^{[16]}$ or RappazDrezet-Gremaud (RDG), ${ }^{[17]}$ relate the cracking susceptibility to the fraction solidified, $f_{\mathrm{S}}$, as described in ScheilGulliver solidification model. ${ }^{[17-19]}$ The CSD model related the time period when the material is most vulnerable to cracking, i.e., $f_{\mathrm{S}}=0.9$ to 0.99 , to the time period available for thermal stress relief, i.e., $f_{\mathrm{S}}=0.4$ to $0.9 .^{[16,18]}$ The boundaries of the time period set by $f_{\mathrm{S}}$ in the CSD model are somewhat arbitrary, because they can change from alloy to alloy. ${ }^{[20]}$ The RDG model is more sophisticated, but requires cracking initiation by void formation due to a drop in cavitation pressure, which was determined by Coniglio and Cross ${ }^{[21]}$ to be unlikely to occur in Alalloys. ${ }^{[17]}$

Recently, Kou [13] proposed a simple yet elegant cracking criterion that relates the cracking susceptibility directly to $f_{\mathrm{S}}$, or more specifically, the $f_{\mathrm{S}}^{1 / 2}$. Kou found that the magnitude of the cracking susceptibility, as a function of solute concentration, is directly correlated to the absolute value of the steepness of the temperature versus $f_{\mathrm{S}}^{1 / 2}$ curve, i.e., $\left|\mathrm{d} T / \mathrm{d} f_{\mathrm{S}}^{1 / 2}\right|$, when $f_{\mathrm{S}}^{1 / 2}$ nears 1 (i.e., complete solidification). Furthermore, Kou ${ }^{[22]}$ demonstrated that the concentration of solute where the maximum crack susceptibility is found will shift to a higher solute concentration due to diffusion in solid. The effect of diffusion is governed by the cooling rate and total freezing time. ${ }^{[13,23]}$ Since the cooling rates in LPBF have shown to be on the orders of $10^{5}$ to $10^{7} \mathrm{~K} / \mathrm{s},{ }^{[24]}$ the influence of diffusion may be different than that for conventional casting with typical cooling rates on the orders of $10^{1}$ to $10^{3} \mathrm{~K} / \mathrm{s}^{[25]}$

In this paper, the role of diffusion on the crack susceptibility calculated by Kou's criterion, is determined for $\mathrm{Al}-\mathrm{Si}, \mathrm{Al}-\mathrm{Mg}$, and $\mathrm{Al}-\mathrm{Cu}$ binary alloys. Quantitative microstructural measurement of sub-grain cell size and solidification crack density from binary Al-Si and other commercial alloys produced by LPBF, are examined to corroborate the effects of alloy composition and solid-state diffusion kinetics on cracking susceptibility relevant to LPBF.

\section{Solidification Cracking Criterion}

In Kou's cracking criterion, ${ }^{[13]}$ the cracking susceptibility is directly related to the $f_{\mathrm{S}}$, which can be determined from the work by Gulliver and Scheil. ${ }^{[19,23]}$ The "Scheil equation" is expressed as:

$f_{\mathrm{S}}=1-\left(\frac{T_{\mathrm{M}}-T}{T_{\mathrm{M}}-T_{\mathrm{L}}}\right)^{\frac{1}{k-1}}$

where $T$ is temperature, $T_{\mathrm{M}}$ is the melting temperature of the solvent, $T_{\mathrm{L}}$ is temperature of the liquidus, $k$ is the partition coefficient that defines the ratio of the concentration of solid, $C_{\mathrm{S}}$, to the concentration of liquid, $C_{\mathrm{L}}$, as:

$k=\frac{C_{\mathrm{S}}}{C_{\mathrm{L}}}$.

This form of Scheil equation assumes that there is infinite diffusion in the liquid, no diffusion in the solid, and that the liquidus and solidus are straight lines, giving a constant $\mathrm{k}$. The fraction eutectic, $f_{\mathrm{E}}$, can then be expressed by:

$f_{\mathrm{E}}=1-f_{\mathrm{S}}=\left(\frac{T_{\mathrm{M}}-T_{\mathrm{E}}}{-m_{\mathrm{L}} C_{0}}\right)^{\frac{1}{k-1}}$

where $C_{0}$ is the concentration, and $-m_{\mathrm{L}}$ is the slope of the liquidus expressed as:

$-m_{\mathrm{L}}=\frac{\left(T_{\mathrm{M}}-T_{\mathrm{E}}\right)}{C_{\mathrm{E}}}$.

In Eq. (4), $T_{\mathrm{E}}$ is the eutectic temperature and $C_{\mathrm{E}}$ is the concentration of solute at the eutectic. Kou ${ }^{[13]}$ suggested that the effect of $f_{\mathrm{S}}$ is more emphasized with $f_{\mathrm{S}}^{1 / 2}$, as per the strain rate based criterion described in the literature. ${ }^{[13,26]}$ Moreover, the steepness of the temperature versus $f_{\mathrm{S}}^{1 / 2}$ curves, $\left|\mathrm{d} T / \mathrm{d} f_{\mathrm{S}}^{1 / 2}\right|$, is directly related to the cracking susceptibility. The $\left|\mathrm{d} T / \mathrm{d} f_{\mathrm{S}}^{1 / 2}\right|$, can be written as:

$\left|\frac{\mathrm{d} T}{\mathrm{~d} f_{\mathrm{S}}^{1 / 2}}\right|=\frac{2(1-k)\left(T_{\mathrm{M}}-T_{\mathrm{E}}\right) \sqrt{1-f_{\mathrm{E}}}}{f_{\mathrm{E}}}$.

The parameter $\left|\mathrm{d} T / \mathrm{d} f_{\mathrm{S}}^{1 / 2}\right|$ is a function of temperature, therefore, to determine the correct value of $\left|\mathrm{d} T / \mathrm{d} f_{\mathrm{S}}^{1 / 2}\right|$, Kou ${ }^{[13]}$ suggested that there should be a range of $f_{\mathrm{S}}$ near $f_{\mathrm{S}}=1$, i.e., near $f_{\mathrm{S}}>0.9$, that represents the maximum $\left|\mathrm{d} T / \mathrm{d} f_{\mathrm{S}}^{1 / 2}\right|$ of the solidification curves. However, it can be difficult to choose an appropriate range of $f_{\mathrm{S}}$ for all compositions because not all compositions achieve $>f_{\mathrm{S}}=0.9$ before reaching the eutectic temperature, making it hard to be consistent with choosing the correct $\left|\mathrm{d} T / \mathrm{d} f_{\mathrm{S}}^{1 / 2}\right|$. In this study, the proper $\left|\mathrm{d} T / \mathrm{d} f_{\mathrm{S}}^{1 / 2}\right|$ will be taken as the final value of $f_{\mathrm{S}}^{1 / 2}$ before reaching the eutectic temperature for each, individual composition.

To account for the effects of diffusion, Kurz and Fisher ${ }^{[23]}$ modified the Scheil equation as

$f_{\mathrm{S}}=\frac{1}{1-2 \alpha^{\prime} k}\left[1-\left(\frac{T_{\mathrm{M}}-T}{-m_{\mathrm{L}} C_{0}}\right)^{\frac{1-2 \alpha^{\prime} k}{k-1}}\right]$

where:

$\alpha^{\prime}=\alpha\left[1-\exp \left(-\frac{1}{\alpha}\right)\right]-\frac{1}{2} \exp \left(-\frac{1}{2 \alpha}\right)$

and 


$$
\alpha=\frac{4 D_{\mathrm{s}} t_{\mathrm{f}}}{\lambda_{2}^{2}}
$$

In Eq. (8), the $D_{\mathrm{S}}$ is the diffusion coefficient in solid, $t_{\mathrm{f}}$ is the freezing (solidification) time, and $\lambda_{2}$ is the secondary dendrite arm spacing (SDAS). The diffusion parameter, $\alpha$, is usually less than 0.3 , and $\alpha=0$ represents the case of no solid-state diffusion. The $t_{\mathrm{f}}$ can be expressed as the freezing range, $\Delta T$, over the cooling rate, $\dot{\mathrm{T}}$ :

$t_{\mathrm{f}}=\frac{\Delta T}{\dot{T}}$.

\section{Cracking Susceptibility and Effect of Diffusion}

Al-alloys are typically alloyed with $\mathrm{Si}, \mathrm{Mg}$, and/or $\mathrm{Cu}$ for strengthening in 5xxx, 6xxx, and 7xxx series. ${ }^{[27]}$ Therefore, it is worthwhile to start the examination of the cracking susceptibility for binary $\mathrm{Al}-\mathrm{Si}, \mathrm{Al}-\mathrm{Mg}$, and $\mathrm{Al}-\mathrm{Cu}$ systems. The hypo-eutectic regions of the phase diagrams for these systems are presented in Fig. 1. For simplicity in using the Scheil equation, the liquidus and solidus were drawn with straight lines. Being well-established, the equilibrium phase diagram for each composition was chosen over any based on nonequilibrium conditions.

More recently, investigators have utilized the CALculation of PHAse (CALPHAD) diagram computations to predict the formation of brittle phases and possible crack susceptibility in complex Ni-base superalloy systems. ${ }^{[28-30]}$ Without a doubt, these computational tools are powerful methods that can utilize Scheil solidification modeling to predict cracking susceptibility of alloy systems, both simple and complex. However, the goal of this work was to

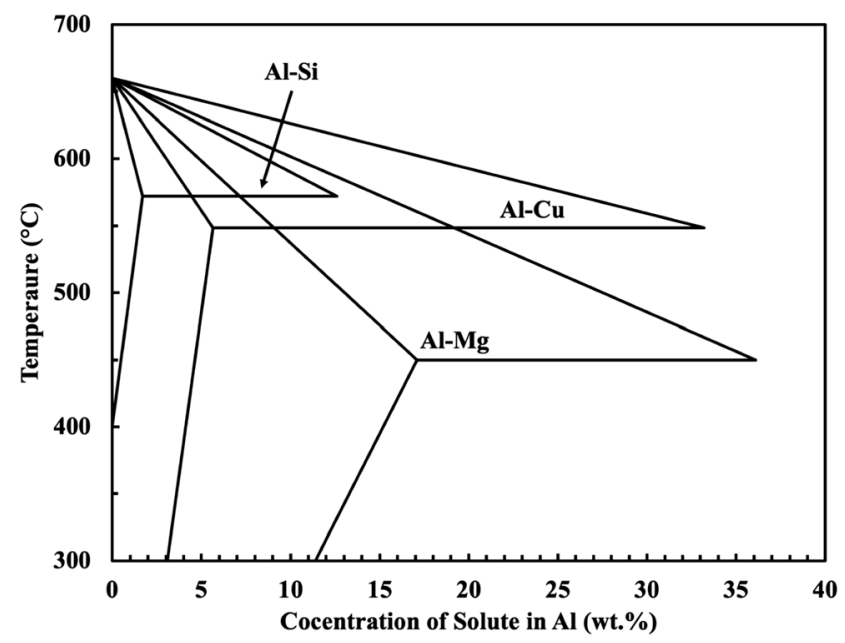

Fig. 1 Hypo-eutectic region of the phase diagram for binary Al-Si, $\mathrm{Al}-\mathrm{Mg}$, and $\mathrm{Al}-\mathrm{Cu}$ systems. ${ }^{[8]}$ Liquidus and solidus were estimated straight lines demonstrate the effectiveness of the simple model, under the original constraints of the Scheil equation. More importantly, some CALPHAD tools, cannot accommodate the effect of solid-state diffusion in the Scheil modeling, which was an important aspect to the current work.

Using Eq. (1), the $f_{\mathrm{S}}^{1 / 2}$ was calculated for varying concentration of solutes, $\mathrm{Si}, \mathrm{Mg}$, and $\mathrm{Cu}$ in $\mathrm{Al}$ as shown in Fig. 2. With a decrease in solute concentration, the magnitude of $f_{\mathrm{S}}^{1 / 2}$ just before reaching the eutectic temperature increased for all alloys. All $f_{\mathrm{S}}^{1 / 2}$ versus temperature curves were drawn to the eutectic temperature in Fig. 2. Understandably, compositions below the solubility limit would have a higher solidus temperature, above the eutectic temperature. However, based on the Scheil condition, these compositions will nearly fully solidify, i.e., $f_{\mathrm{S}}^{1 / 2}=0.99$, at the solidus temperature, but will not completely reach $f_{\mathrm{S}}^{1 /}$
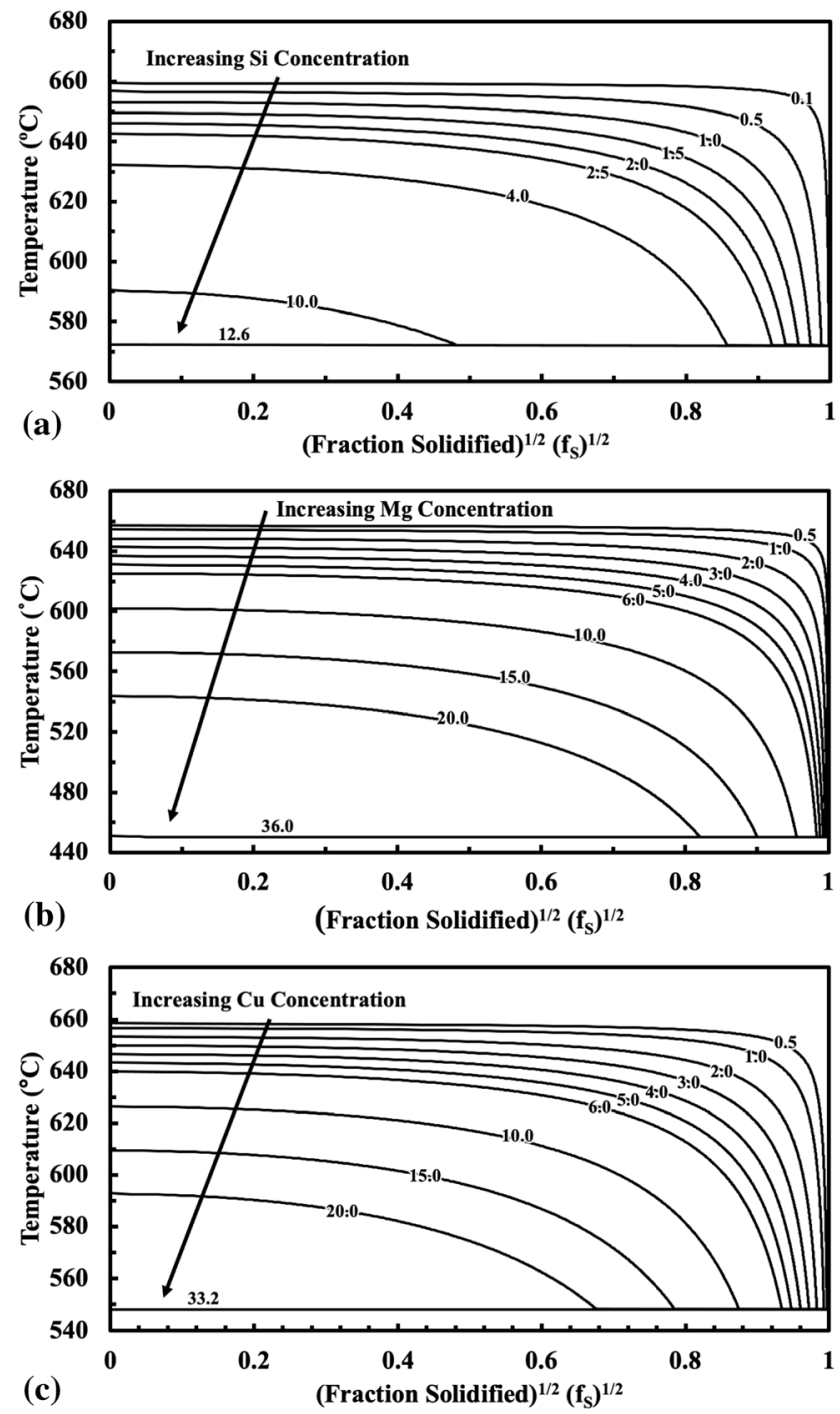

Fig. 2 Temperature vs. fraction solidified, $f_{\mathrm{S}}^{1 / 2}$ curves calculated from Scheil model for Al-alloy with varying concentration of solutes: (a) $\mathrm{Si}$, (b) $\mathrm{Mg}$, and (c) $\mathrm{Cu}$ 
${ }^{2}=1$ until the eutectic temperature is reached. For example, the composition Al-0.1 wt.\% $\mathrm{Si}$ will achieve $f_{\mathrm{S}}^{\mathrm{l} /}$ ${ }^{2}=0.99$ at approximately $639.3{ }^{\circ} \mathrm{C}$, near the solidus temperature for that composition, but will not completely solidify until the eutectic temperature is achieved.

From Fig. 2, $\left|\mathrm{d} T / \mathrm{d} f_{\mathrm{S}}^{1 / 2}\right|$ was calculated using Eq. (5) as presented in Fig. 3 for these binary systems as $f_{\mathrm{S}}^{1 / 2}$ approached complete solidification. Not all compositions achieved $f_{\mathrm{S}}^{1 / 2}=0.99$ before reaching the eutectic temperature. Therefore, the critical $f_{\mathrm{S}}^{1 / 2}$ at which the largest value of $\left|\mathrm{d} T / \mathrm{d} f_{\mathrm{S}}^{1 / 2}\right|$ is found, was employed as the final value of $f_{\mathrm{S}}^{1 / 2}$ before reaching the eutectic temperature for each individual composition. As shown in Fig. 3, with an assumption of "no diffusion in solid," i.e., $\alpha=0$, the maximum cracking susceptibility for the $\mathrm{Al}-\mathrm{Si}, \mathrm{Al}-\mathrm{Mg}$, and $\mathrm{Al}-\mathrm{Cu}$ alloys occurred at $0.5,4.5$, and $1.0 \mathrm{wt} . \%$, respectively. The $6 \mathrm{xxx}$ series Al-alloys contain up to 0.5 to $1.0 \mathrm{wt} . \% \mathrm{Si}, 5 \mathrm{xxx}$ series alloys contain up to 4.0 to $5.0 \mathrm{wt} . \% \mathrm{Mg}$, and many $7 \mathrm{xxx}$ alloys contain 1.0 to $2.0 \mathrm{wt} \% \mathrm{Cu}$. These alloy compositions correspond close to the compositions of
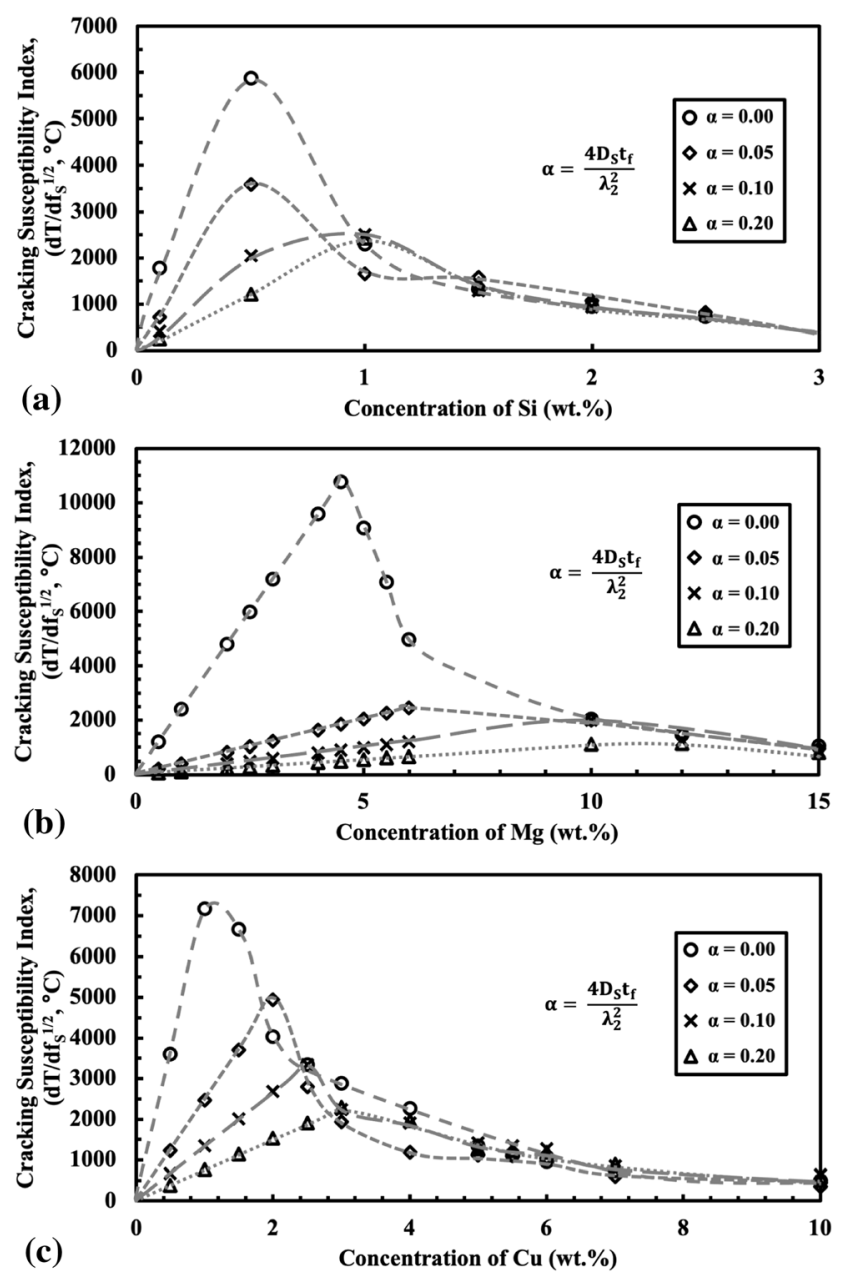

Fig. 3 Crack susceptibility index, $\left|\mathrm{d} T / \mathrm{d} f_{\mathrm{S}}^{1 / 2}\right|$ as a function of solute concentration for (a) $\mathrm{Si}$, (b) $\mathrm{Mg}$, and (c) $\mathrm{Cu}$ in Al-alloys maximum crack susceptibility for each alloy. However, many of these alloys are known to behave well during casting or welding. Therefore, "diffusion in solid" may play an important role for large-scale casting or welding.

To understand the effect of diffusion, the diffusion parameter, $\alpha$, defined in Eq. (8), was varied at 0 (no diffusion), $0.05,0.10$, and 0.20 , to calculate the $f_{\mathrm{S}}^{1 / 2}$ using Eq. (6) for Al-0.5 wt.\% Si, Al-4.5 wt.\% Mg, and Al-1.0 wt.\% $\mathrm{Cu}$, i.e., binary compositions with maximum cracking susceptibility shown in Fig. 3. As presented in Fig. 4, the steepness of the solidification curves reduced significantly with an increase in $\alpha$ parameter, and in some instances, the melt solidified completely before reaching the eutectic temperature. The $\left|\mathrm{d} T / \mathrm{d} f_{\mathrm{S}}^{1 / 2}\right|$ calculated as function of $\alpha$ is also presented in Fig. 3 where an increase in $\alpha$ parameter shifted the maximum crack susceptibility to higher solute
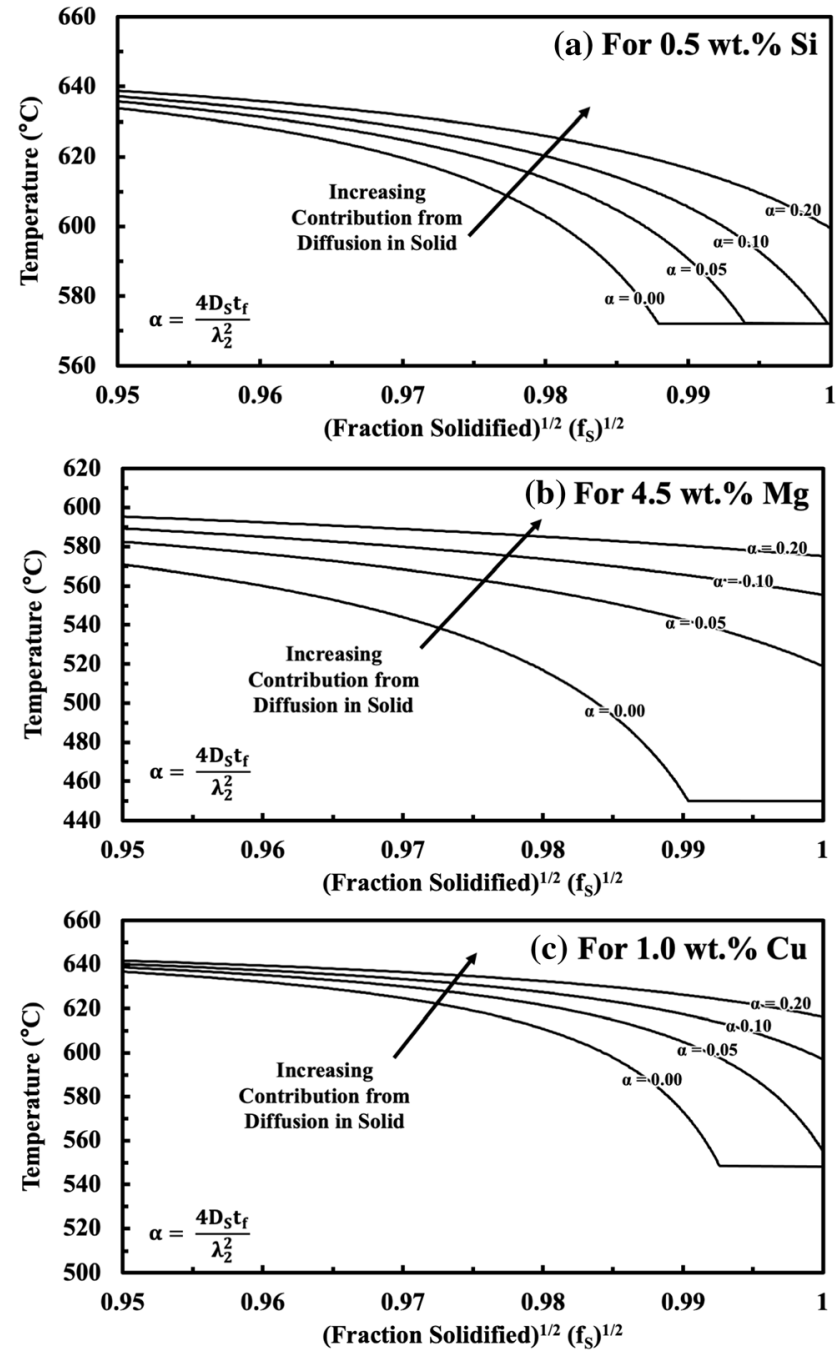

Fig. 4 Temperature vs. fraction solidified, $f_{\mathrm{S}}^{1 / 2}$ curves calculated from Scheil model for (a) Al-0.5 wt.\% Si, (b) Al-4.5 wt.\% Mg, and (c) Al$1.0 \mathrm{wt} . \% \mathrm{Cu}$ alloys with variation in contribution from diffusion in solid quantified by the $\alpha$ parameter 
concentrations, and the overall magnitude of $\left|\mathrm{d} T / \mathrm{d} f_{\mathrm{S}}^{1 / 2}\right|$ decreased significantly. Notably, the Al-Mg alloy showed a drastic decrease in cracking susceptibility with just a minor increase in $\alpha$ to a value of 0.05 .

Since $\alpha$ parameter depends on the freezing time, and thus the cooling rate, the magnitude of $\alpha$ can change significantly with varying cooling rate. It has been reported that in LPBF, the cooling rates are on the orders of $10^{5}$ to $10^{7} \mathrm{~K} / \mathrm{s}$, as compared to $10^{1}$ to $10^{3} \mathrm{~K} / \mathrm{s}$ found in conventional processes such as casting. ${ }^{[24,25]}$ Therefore, a proper magnitude of $\alpha$ must be evaluated to understand the effect of diffusion in solid on the LPBF of Al-alloys.

\section{Cracking Susceptibility and Effect of Diffusion for LPBF AlSi10Mg}

In previous work, Hyer et al. ${ }^{[31]}$ examined the effects of varying LPBF parameters on the microstructural development of AlSi10Mg alloys. In general, a web-like, sub-grain cellular-solidification structure defined by the Al-Si eutectic at the intercellular boundaries, were observed. In addition, the size of the cellular structure increased with a decrease in laser scan speed. This change in cell size was attributed to the change in cooling rate based on the LPBF parameters employed, which changes the energy input. To calculate the cooling rate based on the cell size, Hyer et al. ${ }^{[31]}$ used a phenomenological relationship that correlates the cooling rate to the SDAS expressed by:

$\mathrm{SDAS}=A \dot{T}^{-n}$

where $A$ and $n$ are constants, determined to be $A=43.2$ and $n=0.324$ by Matyja et al. ${ }^{[32]}$ for Al-alloy, and the cell size was used in leu of the SDAS. For the LPBF parameters examined, the cell size and cooling rate were found to be approximately 0.2 to $0.7 \mu \mathrm{m}$ and $10^{5}$ to $10^{7} \mathrm{~K} / \mathrm{s}$, respectively.

Using the experimental results reported by Hyer et al. [31] for LPBF AlSi10Mg alloy, the $\alpha$ parameter was determined with Eq. (8) as shown in Fig. 5. The $t_{f}$ was calculated employing a $\Delta \mathrm{T}$ of $18 \mathrm{~K}$ for $\mathrm{Al}-10 \mathrm{wt} \% \mathrm{Si}$ (from equilibrium phase diagram), and the $\dot{\mathrm{T}}$ was calculated using Eq. (10) from each respective cell size experimentally measured. ${ }^{[31]} \mathrm{A} D_{\mathrm{S}}$ of $10^{-12} \mathrm{~m}^{2} \cdot \mathrm{s}^{-1}$ for Al-Si at $600{ }^{\circ} \mathrm{C}$ was taken from. ${ }^{[33]}$ As presented in Fig. 5(a), $\alpha$ varied between $1 \times 10^{-4}$ and $3.5 \times 10^{-4}$, and its magnitude increased with an increase in cell size as the scan speed decreased. Consequently, an increase in scan speed yielded faster cooling rate, which corresponded to a decrease in $\alpha$ as shown in Fig. 5(b). In other words, hypothetically, a continuously decreasing the scan speed (towards a stationary laser beam) would increase $\alpha$,
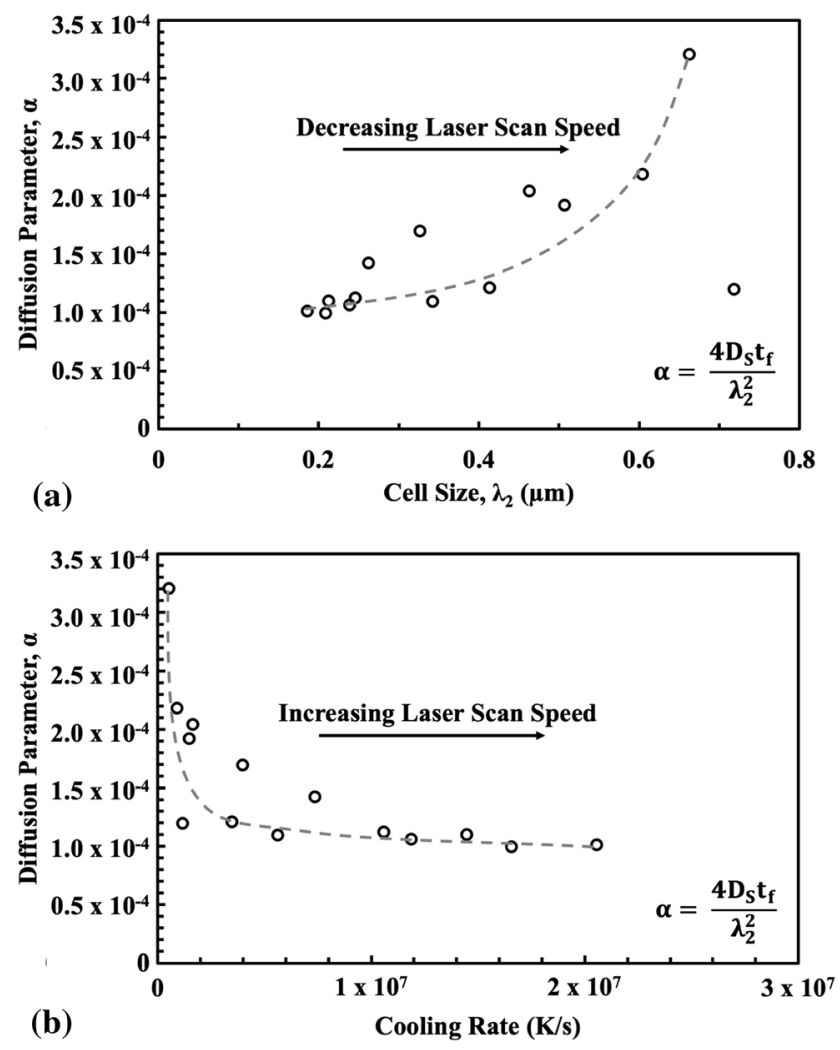

Fig. 5 Calculated diffusion parameter $\alpha$ from Eq. (7) as a function of (a) cell size, and (b) cooling rate determined for LPBF AlSi10Mg alloys ${ }^{[28]}$

allowing for unlimited diffusion in solid to occur. However, Hyer et al. ${ }^{[31]}$ reported excessive formation of keyhole porosity at very low and impractical scan speeds for the AlSi10Mg alloys examined. Therefore, for LPBF, the likely magnitude of $\alpha$ is less than $3.5 \times 10^{-4}$, suggesting that the diffusion solid may be severely limited.

Of course, Eq. (8) for $\alpha$ depends on the diffusion coefficient in solid. For this study, $D_{\mathrm{S}}$ of $10^{-12} \mathrm{~m}^{2} \cdot \mathrm{s}^{-1}$ for Al-Si at $600{ }^{\circ} \mathrm{C}$ was utilized based on the literature ${ }^{[33]}$ However, $\alpha$ can change significantly with slight variance of $D_{S}$, for example with ternary alloying addition such as $\mathrm{Mg}$. For various SDAS, based on those experimentally observed in AlSi10Mg alloys shown in Fig. 5), $\alpha$ was calculated as a function of $D_{\mathrm{S}}$ as shown in Fig. 6. As $D_{\mathrm{S}}$ increased, the $\alpha$ parameter increased at a constant cooling rate, which would reduce the crack susceptibility. For example, diffusion in solid in contact with liquid with $D_{\mathrm{S}}$ of $10^{-10} \mathrm{~m}^{2} \cdot \mathrm{s}^{-1}$ in $\mathrm{Al}$ alloy would yield the $\alpha$ parameter close to 0.02 to 0.2 , given the experimental measured cell size of 0.2 and $0.7 \mu \mathrm{m}$, respectively, as shown in Fig. 6, and may contribute significantly to the mitigation of LPBF cracking as presented in Fig. 3(a). 


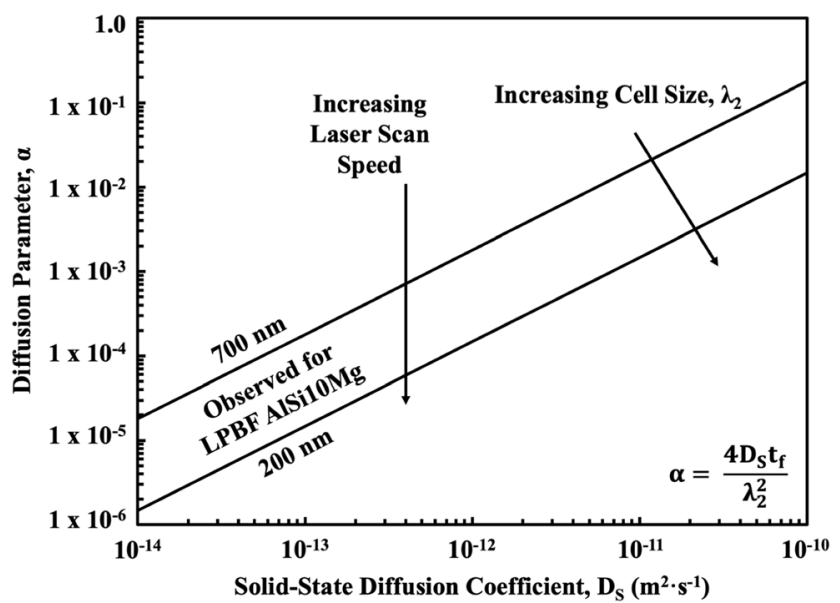

Fig. 6 Variation of diffusion parameter $\alpha$ with diffusion coefficients in solid with respect to the cell size variation typically observed experimentally. For AlSil0Mg alloy, estimated $D_{S}$ and $T$ of $10^{-12} \mathrm{~m}^{2} \mathrm{~s}^{-1}$ and $10^{6} \mathrm{~K} \mathrm{~s}^{-1}$, respectively, yield diffusion parameter $\alpha$ between $10^{-4}$ and $10^{-3}$. An increase in $D_{\mathrm{S}}$ to $10^{-10} \mathrm{~m}^{2} \mathrm{~s}^{-1}$ yields $\alpha$ parameter between 0.02 and 0.2 , which corresponds to a significant contribution to a reduction in hot cracking susceptibility

\section{Cracking Susceptibility of AA5083 Alloy}

AA5083 with $4.0 \sim 5.0$ wt. $\% \mathrm{Mg}, 0.4 \sim 1.0$ wt. $\% \mathrm{Mn}$ ${ }^{[27]}$ is widely used in marine applications, and is known to be both castable and weldable. ${ }^{[27]}$ However, investigators Zhou et al. ${ }^{[5]}$ clearly demonstrated that processing of corrosion resistant AA5083 by LPBF resulted in solidification cracking, regardless the LPBF parameter employed.

In the study by Zhou et al., ${ }^{[5]}$ the cracking density and composition of alloying elements were measured as a function of varying scan speed for high and low laser powers of 350 and $200 \mathrm{~W}$, respectively. The crack density measured was plotted against the concentration of $\mathrm{Mg}$ in Fig. 7. Note that the concentration of $\mathrm{Mg}$ in the powder feedstock was constant for all AA5083 samples built, but the change in $\mathrm{Mg}$ concentration as a function of scan speed was reported due to the evaporation/high-vapor-pressure of $\mathrm{Mg}$ from varying heat input. In other words, higher heat or energy input resulted in a loss of $\mathrm{Mg}$, while $\mathrm{Mg}$ concentration was retained by lower heat or energy input. ${ }^{[34]}$ Fortunately, the optimum LPBF parameters identified that produced dense, crack-free AA5083 with $\mathrm{Zr}$ addition corresponded to a negligible loss of $\mathrm{Mg}$. As shown in Fig. 7(a), an increase in scan speed, which corresponds to a lower heat input, produced AA5083 without the loss of $\mathrm{Mg}$ concentration, which however, corresponded to an increase in crack density.

To mitigate the solidification cracking, Zhou et al. ${ }^{[5]}$ added 0.7 wt.\% $\mathrm{Zr}$ to the AA5083, so that the primary $\mathrm{Al}_{3} \mathrm{Zr}$ precipitates can act as heterogenous nucleation sites and eliminate large columnar grains associated with
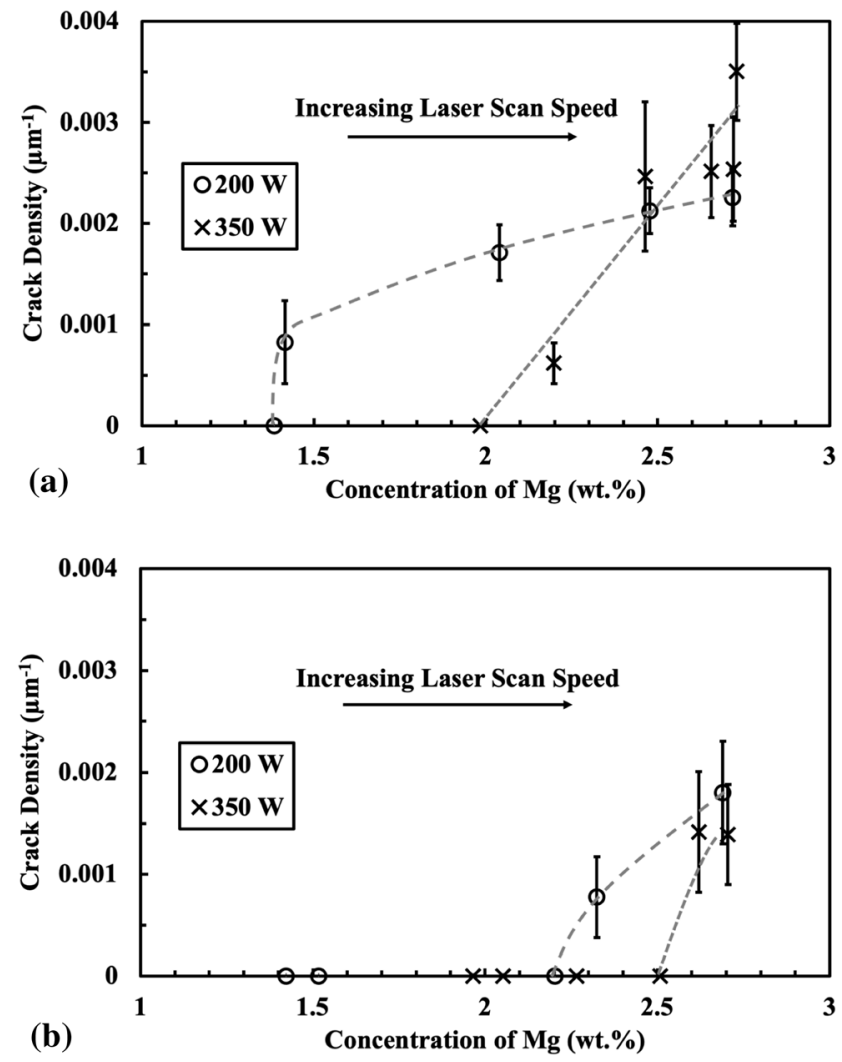

Fig. 7 Experimentally measured cracking density vs. concentration of Mg for AA5083 alloys processed by LPBF: (a) unmodified and (b) alloyed with $0.7 \mathrm{wt} . \% \mathrm{Zr}{ }^{[5]}$

solidification cracking. This change in solidification path allowed for an identification of optimum LPBF parameters, in which AA5083 $+\mathrm{Zr}$ could be built to nearly full density without cracks and negligible $\mathrm{Mg}$ loss. However, in the study by Zhou et al., ${ }^{[5]}$ even with Zr modification, cracking was still observed with faster-than-optimum scan speed, presumably due to changes in cooling rate and the effect of diffusion.

To that end, AA5083 can be examined as a binary Al$\mathrm{Mg}$ alloy. As demonstrated in Fig. 3(b), the maximum cracking susceptibility for the Al-Mg alloy was found at $4.5 \mathrm{wt} . \% \mathrm{Mg}$. With a minor increase in $\alpha$ from 0 to 0.05 assumed by some diffusion in solid, the maximum cracking susceptibility shifts to approximately $6.0 \mathrm{wt} . \% \mathrm{Mg}$, and more importantly, the overall magnitude reduced significantly as shown in Fig. 3(b). Even though the cracking susceptibility is not zero when $\alpha>0$, the severity of cracking would be significantly lower than when $\alpha=0$. The variances in Mg concentration in the AA5083 alloy were dependent on varying scan speed. Moreover, only a few $\mathrm{Mg}$ concentrations were evaluated with no peak in cracking severity observed. Therefore, a more complete study would be warranted for binary Al-Mg alloys before a 
conclusion on the cracking tendency of LPBF Al-Mg alloys can be made.

\section{Cracking Susceptibility of Binary Al-Si Alloy}

To further explore the predictive capability of cracking susceptibility, six binary Al-Si alloys whose compositions were strategically chosen at hypo-, near-, and hyper-eutectic, were gas atomized into alloy powders, and produced into samples by LPBF for microstructural examination with an emphasis on legitimacy of Kou's cracking criterion for LPBF. Procedures for gas atomization and LPBF is briefly summarized, but they have been published elsewhere in details. $^{[5,6]}$

Starting from Al-20 wt.\% Si and pure Al master charges, six binary Al-Si alloy powders were gas atomized by closed-coupled system. Compositions of alloy powders produced were $0.5,1.0,2.0,4.0,12.6$, and 16.0 wt.\% Si. The powder particle size distribution, measured with a particle laser diffractometer (Beckman Coulter LS ${ }^{\mathrm{TM}} 13$ 320), had D10 and D90 values of approximately 20 and $90 \mu \mathrm{m}$, respectively.

SLM 125HL (SLM Solutions) LPBF system equipped with a continuous-wave $\mathrm{Yb}$ fiber laser with a spot size and wavelength of $70 \mu \mathrm{m}$ and $1070 \mathrm{~nm}$, respectively, was utilized in this study. All builds were performed in an inert $\mathrm{N}_{2}$ atmosphere with the $\mathrm{O}$ content lower than $0.5 \%$. The build plate was kept at $100{ }^{\circ} \mathrm{C}$. Simple $12 \mathrm{~mm} \times 12 \mathrm{~mm} \times 12$ $\mathrm{mm}$ cubes were built from each binary alloy powders. After extensive LPBF parametric optimization for each alloy, ${ }^{[35]}$ a laser power, scan speed, hatch spacing, slice thickness, and scan rotation of $350 \mathrm{~W}, 1600 \mathrm{~mm} / \mathrm{s}, 0.13 \mathrm{~mm}$, $0.03 \mathrm{~mm}$, and $67^{\circ}$, respectively were identified to yield microstructure with minimum amount of pores $(<0.1$ vol.\%). To measure crack density, the line intersect method was performed on five optical micrographs taken on asmetallographically polished surfaces.

Cracking was observed in alloys with 1.0 and 2.0 wt.\% Si. A small number of hairline cracks were also found in $0.5 \mathrm{wt} . \% \mathrm{Si}$ but were difficult to distinguish with clarity for quantitative analysis. Representative optical micrographs for solidification cracking observed in the alloy with 1.0 wt.\% Si and for the fully dense alloy with $12.6 \mathrm{wt} . \% \mathrm{Si}$ are presented in Fig. 8. Crack density was determined for each alloy and compared to composition-dependent cracking susceptibility when $\alpha=0$ as shown in Fig. 9. The maximum cracking susceptibility calculated from Eq. (5) and shown in Fig. 3, occurs at $0.5 \mathrm{wt} \% \mathrm{Si}$, while the maximum crack density from experimental investigation was observed at $1.0 \mathrm{wt} \% \mathrm{Si}$. While this slight shift in concentration may be considered insignificant given the experimental uncertainty, Fig. 3(a) indeed shows that an increase in diffusion parameter, $\alpha$, shifts the maximum cracking susceptibility to higher Si concentration. Moreover, Fig. 3(a) shows that the maximum cracking susceptibility occurs at $1.0 \mathrm{wt} . \% \mathrm{Si}$ when $\alpha$ is equal to or greater than 0.1. Singer and Jennings ${ }^{[14]}$ reported maximum severity of cracking at $0.7 \mathrm{wt} . \%$ and $0.8 \mathrm{wt} . \% \mathrm{Si}$ in binary Al-Si alloys using ring casting and clamped weld experiments, respectively.

The Al-Si system was chosen for study to better understand the LPBF process of AlSi10Mg and other Al-Si based alloys commonly used. However, the Al-Si system exhibited only a minor shift in concentration where cracking susceptibility is maximum, demonstrated in Fig. 3. Therefore, it is difficult to determine whether the minor difference in composition between the prediction based on the maximum $\left|\mathrm{d} T / \mathrm{d} f_{\mathrm{S}}^{1 / 2}\right|$ and the experimental crack density measurements, was due to experimental inaccuracy, or was indeed a result of diffusion-assisted mitigation. Due to the drastic change of the solidification curves in Fig. 2 and 3 for binary Al-Mg, it would be fruitful to perform a similar study on LPBF of binary AlMg alloys. Pumphrey and Lyons ${ }^{[36]}$ performed ring cast and restrained weld experiments on binary $\mathrm{Al}-\mathrm{Mg}$ alloys, and reported maximum severity of cracking at approximately 1.0 wt. $\%$ and $4.0 \mathrm{wt} . \%$ for casting and welding, respectively. Therefore, the Al-Mg system may be the best to examine the effect of solid-state diffusion on cracking susceptibility in LPBF.

\section{Summary}

Common commercial Al-alloys known to behave well during casting and welding, cannot be processed with LPBF due to extensive formation of solidification cracking. To help explain the divergence, diffusionless Scheil-Gulliver model was used to determine the fraction solidified as a function of temperature for $\mathrm{Al}-\mathrm{Si}, \mathrm{Al}-\mathrm{Mg}$ and $\mathrm{Al}-\mathrm{Cu}$ binary alloys. The cracking susceptibility was then determined by the steepness of the solidification curves, $\mathrm{ld} T / \mathrm{d} f_{\mathrm{S}}^{1 /}$ ${ }^{2}$, as $f_{\mathrm{S}}^{1 / 2}$ nears complete solidification. Addition of parameter $\alpha$, which incorporates some diffusion in solid at high temperature and the cooling rate, was found to significantly alter the solidification curves and cracking susceptibility. With an increase in $\alpha$ parameter corresponding to more diffusion in solid, the maximum cracking susceptibility shifted to a higher solute concentration, while the magnitude of the cracking susceptibility decreases drastically. Determination of cracking susceptibility defined by $\left|\mathrm{d} T / \mathrm{d} f_{\mathrm{S}}^{1 / 2}\right|$ corresponded well to the solidification cracking experimentally observed in AA5083 (e.g., Al-Mg alloy) and binary Al-Si alloys. Effects of alloy composition and solid-state diffusion kinetics on cracking susceptibility 
Fig. 8 As-polished optical micrographs from the plane parallel to the build direction density in (a) Al-1.0 wt.\% Si and (b) Al-12.6 wt.\% Si alloys used for measuring crack

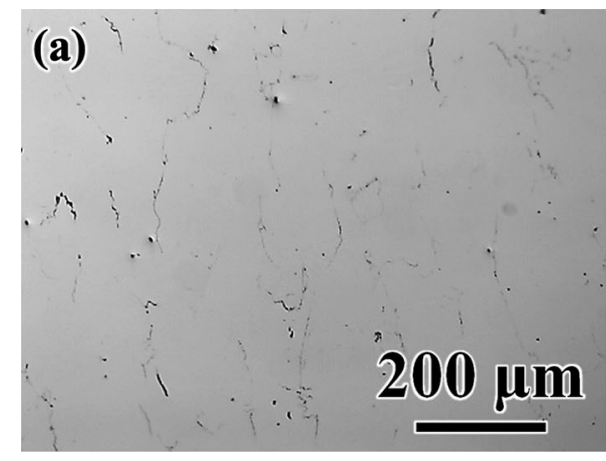

(b)

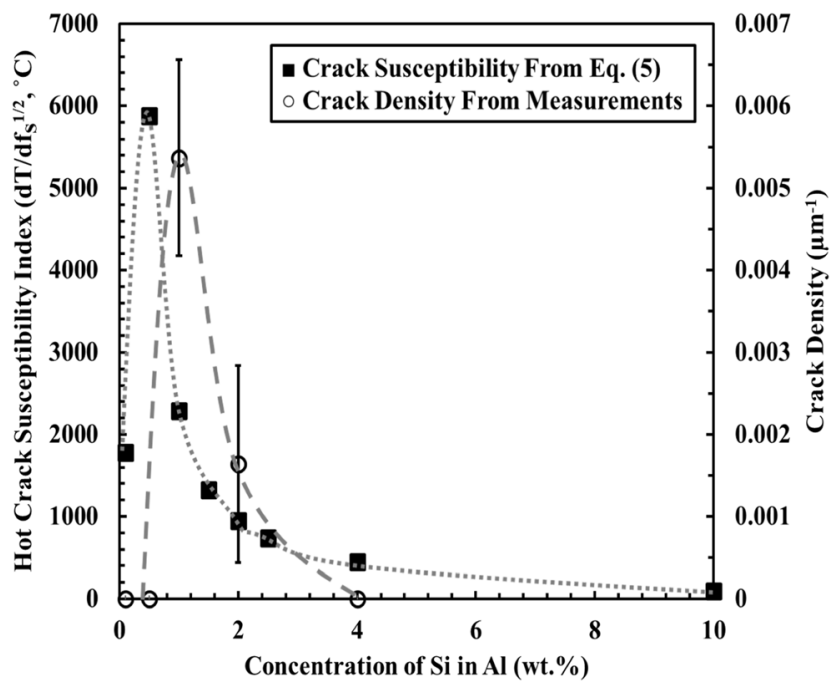

Fig. 9 Hot cracking susceptibility and experimentally measured crack density as a function of Si concentration in binary Al-Si alloys

would be important considerations in designing new alloys or modifying existing commercial alloys specific for LPBF.

Acknowledgment This research was sponsored, in part by the Office of Naval Research (No. N00014-17-1-2559) and in part by the CDCC Army Research Laboratory (No. W911NF1720172). The views, opinions, and conclusions made in this document are those of the authors and should not be interpreted as representing the official policies, either expressed or implied, of the Office of Naval Research or the US Army Research Laboratory or the US Government. The US Government is authorized to reproduce and distribute reprints for Government purposes notwithstanding any copyright notation herein.

\section{References}

1. T. Debroy, H.L. Wei, J.S. Zuback, T. Mukherjee, J.W. Elmer, J.O. Milewski, A.M. Beese, A. Wilson-Heid, A. De, and W. Zhang, Additive Manufacturing of Metallic Components-Process, Structure and Properties, Prog. Mater Sci., 2018, 92, p 112224

2. W.J. Sames, F. List, S. Pannala, R.R. Dehoff, and S.S. Babu, The Metallurgy and Processing Science of Metal Additive Manufacturing, Int. Mater. Rev., 2016, 61(5), p 315-360
3. C. Yap, C. Chua, Z. Dong, Z. Liu, D. Zhang, L. Loh, and S. Sing, Review of Selective Laser Melting: Materials and Applications, Appl. Phys. Rev., 2015, 2(4), p 041101

4. J.H. Martin, B.D. Yahata, J.M. Hundley, J.A. Mayer, T.A. Schaedler, and T.M. Pollock, 3D Printing of High-Strength Aluminium Alloys, Nature, 2017, 549(7672), p 365

5. L. Zhou, H. Hyer, S. Park, H. Pan, Y. Bai, K.P. Rice, and Y. Sohn, Microstructure and Mechanical Properties of Zr-modified Aluminum Alloy 5083 Manufactured by Laser Powder Bed Fusion, Addit. Manuf., 2019, 28, p 485-496

6. L. Zhou, H. Pan, H. Hyer, S. Park, Y. Bai, B. McWilliams, K. Cho, and Y. Sohn, Microstructure and Tensile Property of a Novel AlZnMgScZr Alloy Additively Manufactured by Gas Atomization and Laser Powder Bed Fusion, Scripta Mater., 2019, 158, p 24-28

7. L. Zhou, H. Hyer, S. Thapliyal, R.S. Mishra, B. McWilliams, K. Cho, and Y. Sohn, Process-Dependent Composition, Microstructure, and Printability of Al-Zn-Mg and Al-Zn-Mg-ScZr Alloys Manufactured by Laser Powder Bed Fusion, Metall. Mater. Trans. A, 2020, 51, p 3215-3227

8. H. Okamoto, M.E. Schlesinger, and E.M. Mueller, Eds., ASM Handbook Volume 3: Alloy Phase Diagrams, ASM International, 2016

9. N.T. Aboulkhair, C. Tuck, I. Ashcroft, I. Maskery, and N.M. Everitt, On the Precipitation Hardening of Selective Laser Melted AlSi10Mg, Metall. Mater. Trans. A, 2015, 46(8), p 3337-3341

10. K. Kempen, L. Thijs, J. Van Humbeeck, and J.-P. Kruth, Processing AlSi10Mg by Selective Laser Melting: Parameter Optimisation and Material Characterisation, Mater. Sci. Technol., 2015, 31(8), p 917-923

11. L. Zhou, A. Mehta, E. Schulz, B. McWilliams, K. Cho, and Y. Sohn, Microstructure, Precipitates and Hardness of Selectively Laser Melted AlSi10Mg Alloy Before and After Heat Treatment, Mater. Charact., 2018, 143, p 5-17

12. J.R. Davis, Aluminum and Aluminum Alloys, ASM International, Cleveland, 1993

13. S. Kou, A Criterion for Cracking During Solidification, Acta Mater., 2015, 88, p 366-374

14. A. Singer and P. Jennings, Hot-Shortness of the AluminiumSilicon Alloys of Commercial Purity, J. Inst. Met., 1946, 73(3), p 197

15. G. Sigworth, Hot Tearing of Metals, Trans. Am. Foundrym. Soc., 1996, 14, p 1053-1062

16. T. Clyne, G. Davies, Comparison Between Experimental Data and Theoretical Predictions Relating to Dependence of Solidification Cracking on Composition, in Solidification and Casting of Metals Proceedings of the Conference, Sheffield, England (July 1977, 1979), pp. 275-278

17. M. Rappaz, J.-M. Drezet, and M. Gremaud, A New Hot-Tearing Criterion, Metall. Mater. Trans. A, 1999, 30(2), p 449-455 
18. T. Clyne, M. Wolf, and W. Kurz, The Effect of Melt Composition on Solidification Cracking of Steel, with Particular Reference to Continuous Casting, Metall. Trans. B, 1982, 13(2), p 259-266

19. M.C. Flemings, Solidification Processing, McGraw-Hill, New York, 1974

20. M.A. Easton, M.A. Gibson, S. Zhu, and T.B. Abbott, An A Priori Hot-Tearing Indicator Applied to Die-Cast Magnesium-Rare Earth Alloys, Metall. Mater. Trans., 2014, 45(8), p 3586-3595

21. N. Coniglio and C.E. Cross, Mechanisms for Solidification Crack Initiation and Growth in Aluminum Welding, Metall. Mater. Trans. A, 2009, 40(11), p 2718-2728

22. J. Liu and S. Kou, Effect of Diffusion on Susceptibility to Cracking During Solidification, Acta Mater., 2015, 100, p 359368

23. W. Kurz and D. Fisher, Fundamentals of Solidification, 4th ed., Trans Tech Publications, Zurich, 1998

24. M. Tang, P.C. Pistorius, S. Narra, and J.L. Beuth, Rapid Solidification: Selective Laser Melting of AlSi10Mg, JOM, 2016, 68(3), p 960-966

25. E.A. Lass, M.R. Stoudt, M.E. Williams, M.B. Katz, L.E. Levine, T.Q. Phan, T.H. Gnaeupel-Herold, and D.S. Ng, Formation of the $\mathrm{Ni} 3 \mathrm{Nb} \delta$-Phase in Stress-Relieved Inconel 625 Produced via Laser Powder-Bed Fusion Additive Manufacturing, Metall. Mater. Trans. A, 2017, 48(11), p 5547-5558

26. J. Liu and S. Kou, Crack Susceptibility of Binary Aluminum Alloys During Solidification, Acta Mater., 2016, 110, p 84-94

27. M. Bauccio, ASM Metals Reference Book, ASM International, Cleveland, 1993

28. B. Bocklund, L.D. Bobbio, R.A. Otis, A.M. Beese, and Z.-K. Liu, Experimental Validation of Scheil-Gulliver Simulations for Gradient Path Planning in Additively Manufactured Functionally Graded Materials, Materialia, 2020, 11, p 100689
29. A.R. Moustafa, A. Durga, G. Lindwall, and Z.C. Cordero, Scheil Ternary Projection (STeP) Diagrams for Designing Additively Manufactured Functionally Graded Metals, Addit. Manuf., 2020, 32, p 101008

30. X. Wang, S. Sridar, and W. Xiong, Thermodynamic Investigation of New High-Strength Low-Alloy Steels with Heusler Phase Strengthening for Welding and Additive Manufacturing: HighThroughput CALPHAD Calculations and Key Experiments for Database Verification, J. Phase Equilibria. Diffus., 2020. https:// doi.org/10.1007/s11669-020-00828-y

31. H. Hyer, L. Zhou, S. Park, G. Gottsfritz, G. Benson, B. Tolentino, B. McWilliams, K. Cho, and Y. Sohn, Understanding the Laser Powder Bed Fusion of AlSi10Mg Alloy, Metallogr. Microstruct. Anal., 2020, 9, p 484-502

32. H. Matyja, The Effect of Cooling Rate on the Dendrite Spacing in Splat-Cooled Aluminium Alloys, J. Inst. Metals, 1968, 96, p 3032

33. D.R. Poirier and G. Geiger, Transport Phenomena in Materials Processing, Springer, Berlin, 2016

34. H. Hyer, L. Zhou, G. Benson, B. McWilliams, K. Cho, and Y. Sohn, Additive Manufacturing of Dense WE43 Mg Alloy by Laser Powder Bed Fusion, Addit. Manuf., 33, 101123 (2020)

35. H. Hyer, Understanding Solidification Behavior of Selected Aluminum and Magnesium Alloys Additively Manufactured by Laser Powder Bed Fusion, Doctoral Dissertation, University of Central Florida, Orlando, FL, 2020

36. W. Pumphrey and J. Lyons, Cracking During the Casting and Welding of the More Common Binary Aluminium Alloys, J. Inst. Met., 1948, 74(9), p 439

Publisher's Note Springer Nature remains neutral with regard to jurisdictional claims in published maps and institutional affiliations. 